\title{
Analysis of Young Children's Technology Difficulties and Challenges in Operating and Using Educational Application in Tablet
}

\author{
Chenchen Liu and Jacques Audran
}

\begin{abstract}
Young children between 3-5 years old are in a period of high development of cognitive abilities, like language, literacy and painting. With more access to tablets, it is not only possible to include this technology in teaching curricula but they also show great promise as a learning instrument. In the aim to glean more information concerning children's cognitive development at this precious stage by using a tablet, we invited 25 young children (3-5 years old) coming from a French preschool to participate in this study. We arranged for every child to play an application on the tablet twice a week for two months and adaptively and gradually accommodated instructions to the children according to their performance. Lastly, we analyzed three typical modes of operation on the tablet: simple screen touch, gesture interaction and tilting based on gravity. We found that tilting is the most difficult part for most of the children and challenges are mainly caused by technology difficulty rather than content difficulty.
\end{abstract}

Index Terms-Tablets, technology difficulties, young children, cognitive development.

\section{INTRODUCTION}

\section{A. Technology Integrated into Education}

In the past decades, with the development of communication and information technology, people have more access to technical devices to work and study. Technology integrated into education reflects in both more opportunities to create innovative learning environments [1] and learning activities applied on different groups of people: young children, juniors, college students and adults. From the wide use of technology in education in daily life and the large-scale investment in this field from governments and institutions all around the world, technology integrated into education is not just a fashionable trend but a silver bullet for education reform [2].

The potential of technology blended with education to improve the quality of teaching and learning activities is always highly valued by educators and policy makers. Since the first release of iPad in 2010, this tablet has been the most popular mobile learning device, quickly and widely attracting great focus on its benefits for education because of its numerous advantages such as, high portability, perfect size, multiple touch and easy operation [3]. However, applying the

Manuscript received October 25, 2016; accepted February 17, 2017.

Chenchen Liu is with University of Strasbourg, LISEC, France (e-mail: chenchen.liu@insa-strasbourg.fr).

Jacques Audran is with INSA de Strasbourg, LISEC, France (e-mail: jacques.audran@insa-strasbourg.etu.fr).
iPad to early childhood education still lacks of adequate theoretical and empirical research and the fact that tablets are practical tools in the daily life does not guarantee the possibility of good educational practice with them in the classroom.

\section{B. Debate about Technology Integrated into Education}

Technology is increasingly recognized as an integral tool to improve all kinds of abilities [4], but its variability for education, especially for young children is still inconsistent according to different groups of educators and researchers. On one hand, its effectiveness in cultivating and improving children's abilities and skills has been proven in some fields, like educational games both in computers and tablets applied in many courses such as, mathematics [5], software engineering [6], civil engineering [7], business [8], computer science [9], and language [10] and decision science [11] .On the other hand, the potential negative impact of technology on early childhood education has been conclusive: aggressive and antisocial behaviors caused by violent television and video game [12], less time reading, decreased verbal literacy and even some attention distraction [13] and less face to face social communication are the results. Based on both the positive and negative aspects of technology integrated into education, the effective integration technology into early childhood education still has a long way to go.

Teachers' attitudes and acceptance of technology play a key role in its implementation in the classroom, these two elements have been the subjects of the detailed analysis of the influence factor for teachers in their decision to integrate technology into education. These studies explained the teachers' psychological process to make a decision to accept it or not. Ertmer concluded two different kinds of barriers for teachers to integrate technology [14]. The first type barrier is the lack of time to have the necessary training or technical guidance resulting in inefficient professional development and insufficient access to more technology. The second type barrier is pretty intrinsic and individual, such as teachers' previous experience, ease with new technology and perceived value of the technology. Therefore, we need to take into consideration teachers' subjective acceptance as the first step to implement activities.

\section{Technology Integrated into Early Childhood Education}

Generally speaking, most researches no longer focus on how, whether or to what extent we should use technology with the children, but how we use the technology and how to optimize the design of classroom activities and the interface 
improvement to increase users' certain capacity, ability and skill. Without a doubt, integrating technology into education will develop quickly and deeply, but we need take great account of young children's specific cognitive development characteristics, teachers and parents' perceived value of technology and the interaction between the children, parents and teachers ,aiming to create a young children specific education model to improve young children's engagement, achievement and motivation. Besides, the design of the game, the intervention of the adults and children's development also effect a lot, which also need to be took into consideration.

\section{LITERATURE REVIEW}

\section{A. Advantages of Technology Integration into Young Children's Education}

Two important aspects of integration of technology into young children's education lie on different mobile devices applied and the methods designed to implement combination technology with children's learning activity. With more access of technology devices, tablets, especially iPad in our experimentation, became the most popular device adopting the education field. In this paper, we adopted an iPad as the learning tool because of its sleek profile, large multiple-touch screen and easy access to much information and other reasons [15]. Therefore, four main advantages of iPad integration into young children's education are concluded below:

\section{1) Collaboration}

Based on traditional constructivism theory, learner really got certain skill and knowledge through the process when they do it. Extending the concept of constructivism into social constructivism means that learning happens between different peoples' communication and interaction [16]. Especially for young children, using iPad as the learning tool provide more face to face communication opportunities between the young children because of its portability, which means that collaboration and communication can happen any place [15]. Besides, iPad's multiple touch screen design supports more than one user can operate at the same time [17], which can provide a discussion platform for small groups to finish tasks and children can presents, explain and describe using the rotating scree.

\section{2) Equality}

When technology firstly came to education, parts of educators and researchers firmly opposed to that because they worried about the different finance and social background which played a key role in holding a digital device, will caused inequality and conflict in parents and school. However, using a tablet as a tool to provide a form to implement group project will decrease the inequality on the contrary. During playing a tablet with others to finish a task, everyone can press and touch at the same time, guaranteeing everyone are involved in the activities and less are marginalized.

\section{3) Engagement}

High degree of engagement in learning content and activities is always associated with higher interest and learning effect. An electronic tablet has the similar size with a text book which is easier to be accepted by children who can use a tablet as the formal way when they read a text book. And in time feedback from the tablet is more impressive and provoking to continuously learn, explore and reflect. Besides, the tablet's portability make it possible for children to use it whenever and wherever they are curious about some certain questions, which really stimulate children's leaning interest in virtual learning environment and field trip. Young children's engagement will change a lot during the activities because of many aspects [18]. Therefore the sustainability of engagement should be taken into well consideration. Once the children gained the familiarity of the operation a new device, new activity or even new game, the engagement will drop immediately, therefore, we also need to update and adjust both the devices themselves and learning content to keep the longer time engagement of young children.

Motivation

Since the friendly and brief appearance design and one button with multiple touch interface of the tablet operating system, it immediately caught a lot of attention from the parents, educators and researchers. For young children, various content and easy access to all kind of information is really so attractive, the reward and challenge setting inside the applications of iPad really motivated the children almost during the first time. One of the most important element that tablet stand out it its variety of application for the young children, therefore, the interaction between children and iPad directly refers to the application [15]. Therefore, designing an effective and attractive educational application for young children will be another challenge both for game designers and educators. In this research, our research focus are not only put on the effectiveness on iPad integrated in young children education but also on the designing side referring to a both attractive and educational application which is scientific and totally obeys the law of child development

\section{B. Young Children's Cognitive Development Characteristics}

Early childhood is usually regarded as a period when young children's ability grows and develops very rapidly. Beside, since as indicated that because technology became more accessible in pre-school, young children starts to use some digital devices in class or out of class. In addition, education researchers in young children field strongly support the importance of technology to motivate young children to learn actively and improve the duration of attention and therefore improve young children's ability of logic thinking, problem solving and illustrating an idea. Most recently, majority of point of views on integration of technology, especially tablets, on young children are strongly positive. However, how to better use the technology to facilitate the interaction between the teachers and children will be challenging and should take full consideration of young children's both physical and cognitive characteristics to scientifically implement the activities for teachers and children.

1) Young children's physical characteristics in operating electronic tablets

In this study, we focus on the young children aging from 
3-5 years old, when the languages, writing and painting ability develops quickly, and for most of young children at this age they first start to get access to use tablet. They are curious and not familiar with operation of tablet and even feel nervous about making mistake. Generally young children's physical situation are much weaker compared with the adults, which impacts a lot on their interaction and operation on iPad Because they have smaller fingers, weaker arms, less fine motor control, less manual dexterity and lower speed [19]. Thus, several characteristics operating physically are concluded below:

High dependence degree on familiar way to use digital device. As the independent iPad users, young children's performance present strong preference on the familiar ways that they used before. Since the children stepped out the family environment to go to pre-school, they started to get access to pen-paper work. Having the similar size of the textbook in school made iPads more advanced and easier to be accepted by children comparing with other digital devices, such as PDA, laptop and computer on the desk. However, different from the typical stylus-based interacting, children need to learn use their small and thin finger to touch, write and draw, which will cause children's misunderstanding (For example, they don't understand why their finger can draw on the tablet colorfully) and they need to adapt to this mode of interaction with tablet gradually.

Low speed of hand-eye coordination and low accuracy of target objects. As most of the information-processing theorist indicate, all human information-processing system goes through stimulus input, attention, storage and response output. For young children manipulating an iPad will expose themselves in huge amount of information. Compared with the adults, young children spend more time to understand the instruction of every steps of a task and they also miss out some necessary instruction at the first few try and reduce the time step by step. In addition, due to the imperfect fine-motor skills of young children, the accuracy of both simple touch and multiple touch on the tablet remains challenging and difficult. Therefore, large size of the targets, strongly distinguished difference and simple design of the scene positively help to reduce the delayed time when children spent on understanding the introduction and learning tasks [20].

Lack of experience using tablets and Confusion on multiple operation on the tablets. For most of the young children, they are not dependent users and mostly first have the access to iPad to use is as a learning and entertainment tool. They don't understand the meaning of the pictures and videos on the tablets and even they don't understand why they can use their fingers to touch and draw on the tablets. For young children, the first challenge they must face and overcome would be understanding how to interact with the tablet in front of them. Generally, there exist two different type of operation on the tablet: simple or multiple touches and surface gesture. As of the theory indicated by Vygotsky, the young children's cognitive development advanced through social interactions and problem solving. In the first time of using tablet, young children tend to imitate and copy the behavior of peers and adults, and later they will experience a long time of confusion and loss about complexed operation. Only after a long time of playing a same game or application, they gradually understand and figure out the meaning of every operation.

2) Young children's Cognitive development characteristics

At this age, children's all kinds of abilities start to develop quickly. Their thinking abilities, memory storage, problem solving abilities and capacities of languages and expression will advance a lot through the social interaction and communication with others in this period. Considering the importance of cognitive development for young children, it is quite necessary to analyze and classify young children's general cognitive characteristics to serve for the future analysis of the interaction between young children and tablet suing.

Generally speaking, young children's interest and concentration played the key role of learning activities, focusing time on one game or application could directly illustrate their interest on this object due to young children's shorter concentration time compared with the adults. In addition, it is impossible for young children to use the tablet to play some entertainment games themselves, so integrating the tablet into young children's pedagogy needs to search a proper way to scientifically combine young children's physical and cognitive development with the well-designed learning content and activities. According to Vygotsky's work, children's ability shows significant increase with the support of a More Knowledgeable Other (MKO) (adult or more skilled peer). Therefore, we'd better build a proper platform for children to get information and help from the MKO in time. Thurs, some typical cognitive development characteristics are concluded below:

As is stated by Piaget, children (from 2-7) firmly belong to the period of pre-operation or pre logic. The capacity of memory and the storage amount is limited, so sometime recalling and retelling would be difficult for the children at this age. Besides, they show some disorder and confusion on the time and space, sequence and category. For example they will use yesterday to describe something happening several months ago and they cannot understand the same object could be multiple categorized.

Perceptually-based concentration, egocentric and animism. Most of preschoolers' think methods are quite self-centered and egocentric. They will definitely believe every else just think about the same things that they thought. They are not able to transmit and vary spontaneously and naturally from their own point of view. For example, they will strongly believe that they should have the cookies because they want and everyone will think the same. Besides, another obvious feature in this period is nature and objects are alive with human-like characteristics.

Children's reasoning process in this period is transductive. Some similarities between two objects or the same thing happening to one person in different time will cause their thinking of cause and effect and they will use their own way to explain what happened in their mind. For example, seeing the teacher at school in the morning and in the evening could lead the children to think this teacher must live there. This kind of example explained the logical confusion in young children's mind in a different way.

An important period of leaning to use symbol. The time 
from 3-5 is the heart of symbol development in young children when their language ability does not develop so well. Using symbol includes variety of ability, such as representing one object with some simple letter or picture, understanding the meaning of a map and know how to use a map to locate and understanding the relationship between the tangible objects with symbol, pictures and words. Ability of using symbol really plays a key role in playing a tablet and also could be developed well during the learning process.

TABLE I: DEMOGRAPHIC INFORMATION OF SUBJECT BY AGE

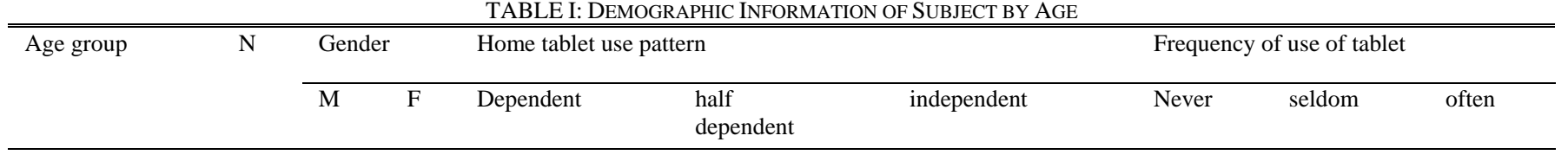

\begin{tabular}{lllllllllll}
\hline 3-4 years & 4 & 1 & 3 & 3 & 1 & 0 & 3 & 0 \\
\hline 4-5 years & 6 & 2 & 4 & 5 & 1 & 0 & 2 \\
\hline 5-6 years & 15 & 8 & 7 & 9 & 3 & 2 & 0 \\
\hline \hline
\end{tabular}

TABLE II: NUMBER OF CHILDREN PASSING EACH PATTERN

\begin{tabular}{lcccc}
\hline \hline Operational pattern & $\begin{array}{l}\text { Succeed at 1st } \\
\text { try }\end{array}$ & $\begin{array}{l}\text { Succeed after } \\
\text { instruction }\end{array}$ & $\begin{array}{l}\text { Succeed after } \\
\text { several practice } \\
\text { with help }\end{array}$ & $\begin{array}{l}\text { Fail to make it } \\
\text { until the end }\end{array}$ \\
\hline Simple screen touch & 20 & 5 & 0 & 0 \\
\hline Surface gesture & 18 & 6 & 1 & 0 \\
\hline tilting & 2 & 22 & 0 & 0 \\
\hline \hline
\end{tabular}

\section{Difficulty Types for Educational Application Designed for Young Children}

As is defined, difficulty refers to something laborious, not easy to do or understand, which requires an effort to be accomplished (Nicholls \& Miller, 1983). In this study, we explained the difficulty for children in the digital setting into the effort and time they spent to overcome the challenge in the learning process. Difficulty could be divided broadly into two types: technology difficulty and content difficulty. Technology difficulty refers to the complexity of game mechanism and setting, the touch and gesture interaction and the ease to understanding the instruction. Content difficulty related to the educational content concluded in the learning activities with tablet or other devices and it differs a lot according to users' age, learning background and cognitive development.

\section{Conclusion}

Integrating the tablets into young children's learning process is quite prospective and variable, this pedagogic instrument evolution positively influenced young children's learning motivation, collaboration and engagement. However, sufficient work to present a practical and well organized learning activities need to fully take consideration of young children's both physical and cognitive characteristics when operating a tablets. Only in this way, it would guarantee the quality of integrated teaching and learning process with tablets.

\section{METHOD}

At this time, this research is pretty exploratory, mixing the qualitative and quantitative approaches. Through field observation, interview and group experiment, we recorded and analyzed the young children's behavior in front of an iPad and explore the children's interaction with tablet and their difficulties using the tablet. A private preschool in Strasbourg, France have been selected because most of children come from a pretty good economy family who can support the tablet use. And besides, the board of directors of this school is combined of parents, which means the parents have the right for all kinds of activities in the school and all the teachers Data collection were finished in 8 weeks in order to get rid of the natural maturation of children, guaranteeing a high internal validity showing in Fig. 2.

\section{A. Subject}

Twenty-five children (11 boys and 14 girls) aging from 3 to 5 years old and coming from a bilingual languages (French and Germen) preschool, Mickele, participated our research activity. All of the children come from different classes and taught by different teachers. Before starting our project in the school, we distributed the background survey to all the parents to know deeply each children's family environment (if they have brothers or sisters at home), previous learning experience with digital device, children's use pattern and frequency of tablet at home and also parents' attitude about tablets' effect to improve children's learning achievement and abilities mentioned in Table I. According to the returning results, most of children in this school come from the middle-income families and high education level and most of the parents holds positive attitude towards the technology integrated into education. In addition, most the children are very no-independent user of tablets, accompanied by parents and the frequency is very low.

\section{B. Procedure}

In a classroom equipped with children size chairs and desks, where is quite familiar with the children, we invited every child to play the iPad alone for 15 fifteen minutes each time and twice a week during the after class time. In order to make sure the internal validity, our project last 8 weeks to get rid of the effect of children's natural maturation.

We selected story-based application<Debout Ludo> specially designed for young children age 3-5. Before we started the project, researchers working as the instructors don't explained how this application work and how to 
operate on the tablet, and we just told the children it is the time to play an interesting game on the iPad, in which there is an interesting story in this game should be retold by the child himself to relax the children and transfer the children attention to the story behind the game. When the children started to play the game, we didn't give any help or explanation about to click or drag and we observed and recorded children's direct reflection and natural behavior in front of an iPad until the children asked help from us showing in Fig. 1, and the instruction is also step by step according children's progress and feedback for the game. In the start of the game, researchers are responsible to set the difficulty for the children based on the child's performance last time from the record.
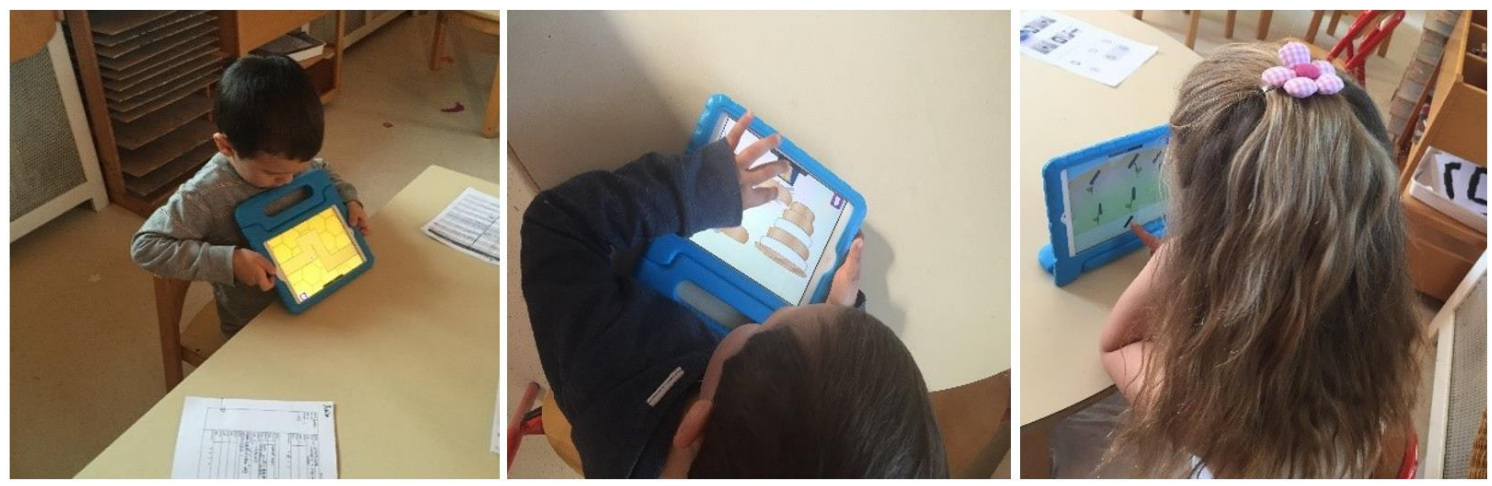

Fig. 1. Three different operational patterns on the tablet.

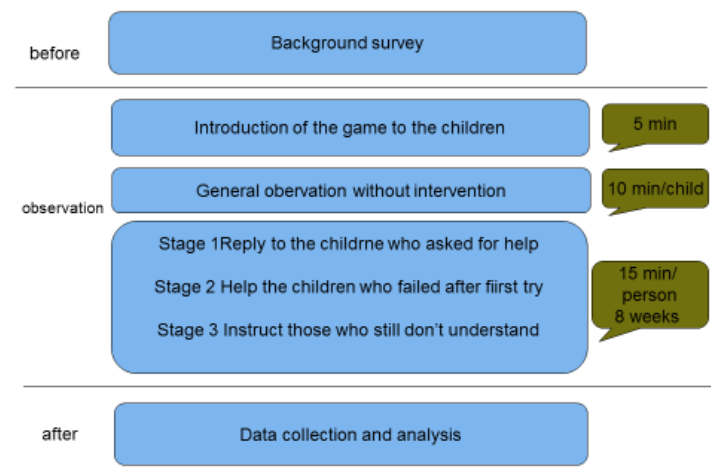

Fig. 2. Project organization.

\section{Data Collection}

The data source mainly come from three aspects: the background data collecting to know deeply the children's learning experience on a tablet before and their family environment, field observation to precisely record each child's working interaction with the tablet and interview with the teachers and the parents who are the mainly support or obstacle for children to use a tablet as learning tool. To address the possible concern of internal validity, we tried to provide familiar and friendly atmosphere for young children and we only provided twice a week (15 minutes each time) for each child to focus on children's real interaction on the tablet. And Fig. 2 explains the whole project organization.

\section{ANALYSIS}

\section{A. Three Typical Behavior Analysis on Tablet}

The most usual mode of behavior on the tablet all present in the application<Debout ludo> in Fig. 1. The simple screen touch ask the children to choose the target according the requesting, where the educational aims is to train children's ability to distinguish different shape, size and colors. The second type of behavior is gesture interaction, which ask the children to finish the gestures drag and drop and use the finger to slide as a painting tool in this game. The third one is tilting based on gravity sense, which ask children to help the figure in the story to pass the road to find princess.

According to our recording for every children, we analyzed the how they passed each challenge and how they reflect when they met some problem. As is indicated in the Table II, most of the children could pass the simple screen touch task and surface gesture task no matter if they have similar gameplay experience. For the tilting part which asked children to take the tablet to change the direction of the figure to find the right way to see the princess, $92 \%$ children could not understand how it works at the first try and some of them tried to use the previous methods like click, drag and drop to finish this task and they failed again. From our observation, most difficult challenge for most of children is mainly caused by their dependence on previous motion. In the mind of children, they believed that since their last movement work, the same movement will also work in the next part, so most children repeated the same movement again and again.

Based on children's behavior overall, their time spent to pass each task, the way they asked for help from the instructors and their reflection of the help, we gave the final difficulty value for three operational patterns on tablet separately. We could see that simple screen touch and surface gesture is much easier for children to accept, understand and operate compared with tilting and it is difficult for children to change one movement to another movement in the same gameplay.

TABLE III: PROPORTION DISTRIBUTION OF TECHNOLOGY AND CONTENT DIFFICULTY'S INFLUENCE

\begin{tabular}{lcc}
\hline \hline & $\begin{array}{l}\text { Technology } \\
\text { difficulty }\end{array}$ & content difficulty \\
\hline Missed touched event & $90 \%$ & $10 \%$ \\
\hline Bad gameplay comprehension & $95 \%$ & $5 \%$ \\
\hline $\begin{array}{l}\text { Misunderstanding the } \\
\text { instruction }\end{array}$ & $70 \%$ & $30 \%$ \\
\hline Delay time & $60 \%$ & $50 \%$ \\
\hline \hline
\end{tabular}

\section{B. Analysis Typical Mistakes Made by Children}

Generally speaking, three typical modes of operation on the tablet, simple screen touch, gesture interaction and tilting are very popular for game designer and developer. However, 
mixing these three different modes into the same game for young children (age3-5) is very challenging. In our project, children behaved several different ways to make a mistake which stop them to go to the next part. In the picture 3 , the first children don't understand how to make a house for the bee, she thought she could click each part and she totally didn't understand the aim of this game, whose aim is to development children's ability to distinguish different sizes. For the second child, she tried to use drag and drop to let the figure go to the place where she wanted to be, but she failed because she didn't understand how to move in this part and she insisted to use drag and drop way and she didn't notice that and felt so confused and a little disappointed. For the third child, she is pretty familiar with using a tablet and she passed the first two tasks in this game much faster than the others but when it came to the third part, she try to tilt the tablet to move the figure in the game just the same as what she did in the first two task and she failed of course. For the fourth child, he is an elder boy, when he first tried to pass the task, he didn't understand he should tilt the tablet and he insisted to use the finger to drag and touch, the figure moved really so slowly.
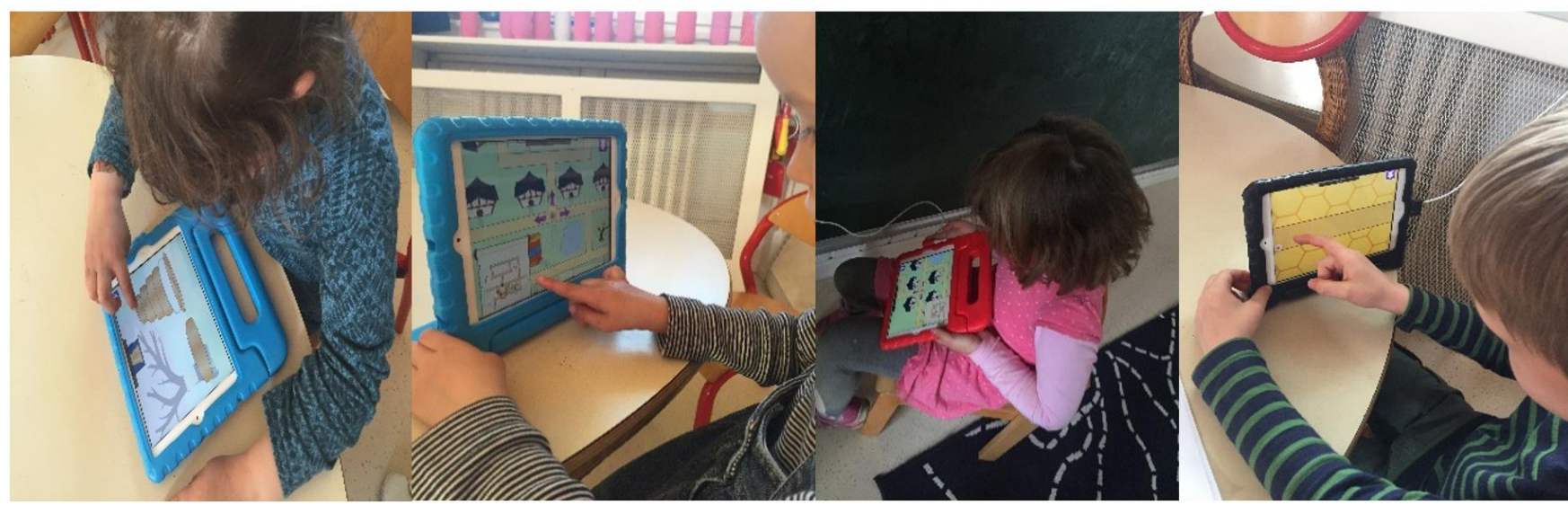

Fig. 3. Typical mistakes made by children.

In conclusion, these four kinds of mistakes presenting in our project are in mainly the same form - confusion. Young children totally mixed the different modes of operation on the tablet and they are unable to change different mode naturally, consciously and quickly in different tasks.

As is showed in the picture 3, we knew that the causes leading to the stop of game are partially technological and educational content, we recorded each child's every performance especially at their exploring time, we analyzed the different proportion for every item and we got the result to analyze at children's different confused behavior are caused mainly by technology difficulty or content difficulty.

According the record of every child and observation, we calculated three researchers' assessment and concluded that, technology difficulty definitely influence children's understanding the gameplay and caused more missed touch events and bad gameplay comprehension. Comparatively, Table III shows that technology difficulty's influence on children's understanding the instruction from the researchers and delay time is much lower compared with the first two items missed touched event and bad gameplay comprehension, but its effect is still much stronger than content difficulty. In a word, technology difficulty.

\section{RESULT DISCUSSION AND IMPLICATION}

Integrating technology into students' curriculum positively effects learning achievement, motivation, collaboration and innovation. But integrating tablet into preschool education need to adequately take consideration of young children's certain cognitive development to present a suitable and effective platform for them. In this way, we could get scientific and effective learning tool for the young children to develop their skill at their age. According to our analysis, it is concluded below:

Firstly, Mode of operation should be set in simplified way. Among three typical modes of operation, simple screen touch is the easiest and tilting based on gravity is most difficult and children are not able to adapt to the mix of three different mode of operation and not aware of the difference of those different mode of operation. Therefore, simplifying the way to set the mode of operation for young children and it is better to choose one mode in one learning task.

Secondly, Technology difficulty influenced more than content difficulty on young children

Due to the limit of cognition of young children and lack of experience of using a tablet, the biggest challenge for young children is the technological part rather learning content, they spent a long time to adapt to the game play and figure out how to operation in some certain context. Once they overcome the technological part, the different level of learning content will be meaningless for them anymore in a great extent.

In conclusion, designing and developing an application on the tablet should follow the main principle of simplifying, interesting and adapting. Only in this way, young children could improve learning achievement and motivation and develop all kinds of abilities efficiently.

\section{REFERENCES}

[1] G. J. Hwang, N. S.Chen, and J. L. Shih, "Editorial: Shifting from Technology-enhanced learning to technology-transformed learning," in Proc. the Conference APTEL 2010 on Knowledge Management and e-Learning, vol. 3, no 3, pp. 306-309, 2010.

[2] C. K. Blackwell et al., "Adoption and use of technology in early education: The interplay of extrinsic barriers and teacher attitudes," Computers \& Education, vol. 69, pp. 310-319, 2013. 
[3] N. Kucirkova, D. Messer, K. Sheehy et al., "Children's engagement with educational iPad apps: Insights from a Spanish classroom" Computers \& Education, vol. 71, pp. 175-184, 2014.

[4] L. Couse, and D. W. Chen, "A tablet computer for young children? Exploring its viability for early childhood education," Journal of Research on Technology in Education, vol. 43, pp. 75-96, 2010.

[5] R. Eck and J. Dempsey, "The effect of competition and contextualized advisement on the transfer of mathematics skills a computer-based instructional simulation game," Educational Technology Research and Development, vol. 50, no. 3, pp. 23-41, 2002.

[6] N. E. Cagiltay, "Teaching software engineering by means of computer-game development: Challenges and opportunities," British Journal of Educational Technology, vol. 38, pp. 405-415, 2007.

[7] M. Ebner and A. Holzinger, "Successful implementation of user-centered game based learning in higher education: An example from civil engineering," Computers \& education, vol. 49, no. 3, pp. 873-890, 2007.

[8] K. Kristian. "Foundation for problem-based gaming," British Journal of Educational Technology, vol. 38, pp. 394-404, 2007.

[9] P. Marina, "Exploring the potential of computer and video games for health and physical education: A literature review," Computers \& Education, vol. 53, pp. 603-622. 2009.

[10] T.-Y. Liu and Y.-L. Chu, "Using ubiquitous games in an English listening and speaking course: Impact on learning outcomes and motivation," Computers \& Education, vol. 55, no 2, pp. 630-643. 2010

[11] Y.-C. Chang et al., "Examining the effects of learning motivation and of course design in an instructional simulation game," Interactive Learning Environments, 2010, vol. 18, no. 4, pp. 319-339, 2010.

[12] J. Brad et al., "Effects of violent video games on aggressive behavior, aggressive cognition, aggressive affect, physiological arousal, and prosocial behavior: A meta-analytic review of the scientific literature," Psychological science, vol. 12, no. 5, pp. 353-359, 2001.

[13] A. C. Dimitri et al., "Television viewing, computer use, obesity, and adiposity in US preschool children," International Journal of Behavioral Nutrition and Physical Activity, 2007, vol. 4, no 1, pp. 1. 2007.

[14] P. A. Ertmer, "Addressing first-and second-order barriers to change: Strategies for technology integration," Educational Technology Research and Development, vol. 47, no. 4, pp. 47-61, 1999.

[15] H. Sarah and Y. Jeff, "iPad in education: A case study of iPad adoption and use in a primary school," in Proc. 2012 45th Hawaii International Conference on System Science, IEEE. pp. 78-87, 2012.

[16] A. Teara et al., "Constructionism: Student learning and development," Academic Exchange Quarterly, vol. 9, no. 3, pp. 259-267, 2005.

[17] B. Victoria et al., "Around the table: are multiple-touch surfaces better than single-touch for children's collaborative interactions?" in Proc. the 9th International Conference on Computer Supported Collaborative Learning, International Society of the Learning Sciences, pp. 335-344, 2009.

[18] V. Giasemi et al., "Towards a theory of mobile learning," Proceedings of mLearn. pp. 1-9, 2005.

[19] N. Jaye et al., "Interaction and recognition challenges in interpreting children's touch and gesture input on mobile devices," in Proc. the 2012 ACM International Conference on Interactive Tabletops and Surfaces, pp. 225-234, 2012.

[20] A. Craig et al., "Effects of violent video games on aggressive behavior, aggressive cognition, aggressive affect, physiological arousal, and prosocial behavior: A meta-analytic review of the scientific literature," Psychological Science, vol. 12, no. 5, pp. 353-359, 2001.

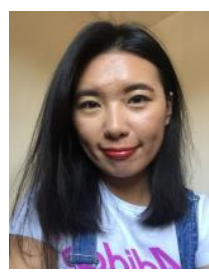

Chenchen Liu was born in China on January 25, 1989.

She got the bachelor degree in management in Harbin Normal University in China in 2012 and she finished her master degree in educational management in Harbin Institute of Technology in 2014. The author's major field of study is game-based learning, early childhood education, mobile learning, and flipped class.

She has been teaching English for undergraduate and high school students mainly in reading skill and writing grammar parts and therefore she had great amount of teaching experience, which provoke her great interest on all kind of research questions both on theoretical and practical educational problem. In 2015, she started to work as a Phd studen in INSA Strasbourg and she began to focus on young children's cognitive development with the tablets. Her research interests conclude both young children and elder students' learning behavior with the information and communication technology.

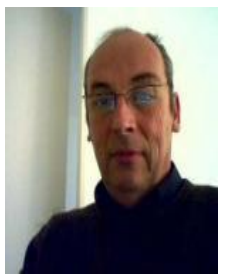

Jacques Audran got his doctor degree in educational sciences in France at Aix-Marseille University in 2001 From 2002 to 2007, he was assistant professor at Mulhouse-Colmar University. He obtained the Habilitation for Direction of Research in Paris at Sorbonne in 2010. From 2011 to now, he is full professor at the National Institute of Applied Sciences in Strasbourg. Prof. Audran's research interests are the use of technology in education and training, he studies the interaction between learners and teachers, and the process of generating innovative ideas. Since 2015 he is also responsible for the digital department of INSA-Strasbourg and he is also a member of the French National Council of Universities. His current research interests cover as well the early childhood education with technology and distance educations. 